\title{
TINGKAT RADIASI ELEKTROMAGNETIK BEBERAPA LAPTOP DAN PENGARUHNYA TERHADAP KELUHAN KESEHATAN
}

\author{
${ }^{1}$ Debby Thandung \\ ${ }^{2}$ Fransiska Lintong \\ ${ }^{2}$ Wenny Supit \\ ${ }^{1}$ Kandidat Skripsi Fakultas Kedokteran Universitas Sam Ratulangi Manado \\ ${ }^{2}$ Bagian Fisika Fakultas Kedokteran Universitas Sam Ratulangi Manado \\ Email: debbythandung09326@yahoo.com
}

\begin{abstract}
Applying physics electromagnetic radiation especially radiation from laptop is important to know about how to prevent it or reduce the risk of exposure body with radiation. The complain about health condition that usually happened are headacne, pain in muscle, lazy eyes and insomnia. The purpose of this research is to measuring electromagnetic radiation level of some laptop and also it's effect to health issue. Methods of this research is the descriptive with cross sectional device. The reasearch is located at Pertamina building and Rusunawa around Sam Ratulangi University's Campus Manado. Samples are 35 laptop of 35 respondent. The data was acquired by using questionnaire and measuring electromagnetic radiation level using Electromagnetic Field Radiation Tester. Analysing data using spearman corelation test.The results of this research show the highest rate of electromagnetic radiation at 0,01-0,10 $\mu \mathrm{T}$ are 27 laptop (77\%), mean while the lowest at 0,41-0,50 $\mu \mathrm{T}$ and the most issue that found is lazy eyes with number of 29 people (83\%). The results of spearman corelation test show there is no relationship that have a meaning between laptop radiation level with health issue.
\end{abstract}

Keywords: electromagnetic radiation, laptop, health issue.

\begin{abstract}
Abstrak:Penerapan ilmu fisika tentang radiasi elektromagnetik khususnya radiasi dari laptop penting untuk mengetahui cara pencegahan atau mengurangi resiko terpaparnya tubuh dengan radiasi. Keluhan kesehatan yang terjadi biasanya sakit kepala, nyeri otot, mata lelah, insomnia. Pada saat sekarang ini terjadi banyak kontroversi mengenai radiasi elektromagnetik terhadap tubuh manusia. Tujuan penelitian untuk mengukur tingkat radiasi elektromagnetik pada beberapa laptop serta pengaruhnya terhadap keluhan kesehatan. Metode penelitian yakni survei deskriptif secara cross sectional. Lokasi penelitian bertempat di gedung Pertamina dan Rusunawa disekitar kampus Universitas Sam Ratulangi Manado. Sampel berjumlah 35 laptop dari 35 responden. Data diperoleh melalui kuesioner dan pengukuran tingkat radiasi elektromagnetik menggunakan alat Electromagnetic Field Radiation Tester. Data dianalisis menggunakan uji korelasi spearman.Hasil penelitian menunjukkan tingkat radiasi gelombang elektromagnetik rata-rata tertinggi pada 0,01-0,10 $\mu \mathrm{T}$ sebanyak 27 laptop (77\%), sedangkan terendah pada 0,41-0,50 $\mu \mathrm{T}$ dan keluhan terbanyak yakni mata lelah dengan jumlah responden sebanyak 29 orang (83\%). Hasil uji korelasi spearman menunjukkan tidak terdapat hubungan yang bermakna antara tingkat radiasi laptop dengan keluhan kesehatan.
\end{abstract}

Kata Kunci: radiasi elektromagnetik, laptop, keluhan kesehatan.

Laptop (notebook/powerbook) adalah komputer portabel (kecil dan dapat dibawa ke mana-mana dengan mudah) yang terintegrasi pada sebuah casing. Beratnya berkisar dari 1 hingga 6 kilogram tergantung dari ukuran, bahan, dan spesifikasi. Sumber listrik berasal dari baterai atau A/C adaptor yang dapat digunakan untuk mengisi ulang baterai dan menyalakan laptop. Baterai laptop pada umumnya dapat bertahan sekitar 1-6 jam. Komponen yang terdapat didalamnya adalah sama dengan yang 
terdapat pada komputer desktop dengan ukuran yang diperkecil, lebih ringan, tidak panas, dan irit listrik. Laptop kebanyakan menggunakan layar LCD (Liquid Crystal Display) berukuran 10 inci hingga 17 inci. Keyboard yang terdapat pada laptop juga dilengkapi dengan touchpad atau trackpad yang berfungsi sebagai penggerak kursor mouse. Keyboard dan mouse tambahan dapat dipasang melalui soket USB (universal serial bus). ${ }^{1}$

Laptop merupakan teknologi yang memungkinkan individu untuk berdaya komputasi tinggi dimanapun ia berada. Namun dengan manfaat tersebut, komputer portabel memiliki kekurangan secara ergonomis. Menurut Hegde, Direktur Human Factors and Ergonomics Laboratory di Universitas Cornell, dilihat dari desainnya laptop tidak pernah dimaksudkan sebagai pengganti komputer desktop. Desain laptop yang begitu portabel semakin menambah potensi resiko ergonomis untuk penggunaan jangka panjang. Beberapa isu ergonomis utama pada laptop diantaranya berkaitan dengan keyboard, monitor, dan alat penunjuk (pointing device). Masalah utamanya seperti yang dijelaskan peneliti di University of North Carolina (UNC) di Chapel Hill School of Medicine adalah berasal dari konstruksi badan laptop yang menyatu yaitu layar dan keyboardsaling berdekatan. Desain keyboard dan monitor yang tak terpisahkan menyebabkan pengguna tidak bebas untuk mengkonfigurasi peralatan mereka dengan cara yang meminimalkan resiko. Tidak seperti komputer desktop, individu tidak dapat mengatur monitor dan keyboard secara independen. $^{2}$

Ide pembuatan laptop dicetuskansejak tahun1970-an. Gagasan tersebut pertama kali diungkapkan oleh Alan Kay, ilmuwan komputer dari Amerika. Proyek laptop pertama ini diberi nama "Osborne 1" dan dirilis pada bulan April 1981 oleh Osborne ComputerCorporation. Alat ini berukuran super besar dan dilengkapi layar monitor 5 in, menggunakan sambungan listrik dengan baterai cadangan, 2 floppy drive ukuran $5 \frac{1}{4} 4$ inci, modem port, dan keyboard. Penemuan ini terus dikembangkan hingga sekarang. ${ }^{3}$
Faktor risiko ergonomi terkait penggunaan laptop, dilihat dari postur tubuh pada saat pemakaian laptop. Frekuensi penggunaan laptop tidak dapat dipisahkan dengan durasi seseorang menggunakan laptop. Walaupun seseorang menggunakan laptop dalam waktu yang lama tapi tidak dalam frekuensi yang sering maka keluhan yang ditimbulkan akan lebih ringan dibandingkan dengan orang yang sering menggunakan laptop. ${ }^{1}$

Laptop merupakan perangkat elektronik yang mengeluarkan sinar radiasi elektromagnetik. Potensi keluhan kesehatan yaitu timbulnya reaksi hipersensitivitas(electrical sensitivity) merupakan masalah kesehatan akibat pengaruh radiasi medan elektromagnetik berupa gangguan fisiologis yang ditandai dengan sekumpulan gejala neurologis dan kepekaan (sensitivitas) terhadap medan elektromagnetik. ${ }^{4}$ Banyak orang yang memiliki sensitivitas terhadap tingkat frekuensi tertentu dari medan elektromagnetik. Gejala-gejala electrical sensitivity yang banyak dijumpai berupa sakit kepala (headache), pening (dizziness), keletihan yang menahun (chronic fatigue syndrome), sukar tidur (insomnia). Beberapa gejala lain yang terkadang dapat dijumpai antara lain berdebar-debar (tachycardia), mual (nausea) tanpa ada penyebab yang jelas, muka terasa terbakar (facial flushing), rasa sakit pada otot-otot (pain in muscles), telinga berdenging (tinnitus), kejang otot (muscle spasms), kebingungan (confusion), gangguan kejiwaan berupa depresi (depression) serta gangguan konsentrasi (difficulty in concentrating).

\section{METODE PENELITIAN}

Penelitian ini menggunakan metode survey deskriptif dengan cara potong lintang (cross sectional) dengan sampel berupa beberapa merek dan tipe laptop yang berbeda dan disertai kuesioner untuk menyaring sampel.Penelitian ini dilakukan dari bulan November 2012 sampai bulan Desember tahun 2012 di Gedung Pertamina dan Rusunawa Universitas Sam Ratulangi Manado.Penelitian ini menggunakan 35 sampel laptop yang berbeda dari 35 
responden dan diberikan kuesioner tentang Tingkat Radiasi Elektromagnetik Beberapa Laptop dan Pengaruhnya Terhadap Keluhan Kesehatan. Alat dan bahan yang digunakan yaitu alat pengukur panjang gelombang elektromagnetik (Electromagnetic Field Tester), 35 sampel laptop dari beberapa merek dagang dan tipe yang berbeda, lembar kuesioner penelitian, alat tulis menulis. Analisis univariat dilakukan secara deskriptif dari masing-masing variabel dengan tabel distribusi frekuensi disertai penjelasan.Analisis bivariat dilakukan untuk melihat hubungan antar variabel. Pada penelitian ini dilakukan uji korelasi Spearman untuk melihat hubungan antara radiasi laptop dan keluhan kesehatan responden.

\section{HASIL}

\section{Karakteristik responden berdasarkan umur}

Distribusi karakteristik responden berdasarkan umur dapat dilihat pada Tabel 1. Tabel 1 menunjukkan sebagian besar responden dalam penelitian ini berusia 21 tahun (40,0\%) sedangkan responden dengan usia 18 dan 23 tahun hanya berjumlah 1 orang (2,9\%).

Tabel 1. Karakteristik responden berdasarkan umur.

\begin{tabular}{ccc}
\hline $\begin{array}{c}\text { Umur } \\
\text { (tahun) }\end{array}$ & $\begin{array}{c}\text { Jumlah } \\
\text { Responden } \\
(\mathbf{N})\end{array}$ & $\begin{array}{c}\text { Persentase } \\
(\mathbf{\%})\end{array}$ \\
\hline 18 & 1 & 2,9 \\
19 & 4 & 11,4 \\
20 & 12 & 34,3 \\
21 & 14 & 40,0 \\
22 & 3 & 8,6 \\
23 & 1 & 2,9 \\
\hline Total & 35 & 100,0 \\
\hline
\end{tabular}

\section{Karakteristik responden berdasarkan jenis kelamin}

Tabel 2 menunjukkan sebagian besar responden dalam penelitian ini berjenis kelamin perempuan berjumlah 33 orang (94,3\%). Responden dengan jenis kelamin laki - laki hanya berjumlah 2 orang (5,7\%).
Tabel 2. Karakteristik responden berdasarkan jenis kelamin.

\begin{tabular}{ccc}
\hline $\begin{array}{c}\text { Jenis } \\
\text { Kelamin }\end{array}$ & $\begin{array}{c}\text { Jumlah } \\
\text { Responden } \\
(\mathbf{N})\end{array}$ & $\begin{array}{c}\text { Presentase } \\
\mathbf{( \% )}\end{array}$ \\
\hline Laki-laki & 2 & 5,7 \\
Perempuan & 33 & 94,3 \\
\hline Total & 35 & 100,0 \\
\hline
\end{tabular}

\section{Karakterisik responden berdasarkan durasi pemakaian laptop}

Tabel 3 menunjukkan sebagian besar responden dalam penelitian ini memiliki durasi pemakaian laptop antara 4-6 jam per hari berjumlah 14 orang (40\%). Responden dengan pemakaian laptop 1-3 jam per hari berjumlah 12 orang $(34,3 \%)$ dan responden dengan pemakaian $<1$ jam per hari hanya berjumlah 2 orang (5,7\%).

Tabel 3. Karakteristik responden berdasarkan durasi pemakaian laptop.

\begin{tabular}{ccc}
\hline $\begin{array}{c}\text { Durasi } \\
\text { (jam) }\end{array}$ & $\begin{array}{c}\text { Jumlah } \\
\text { Responden (N) }\end{array}$ & $\begin{array}{c}\text { Persentase } \\
(\mathbf{\%})\end{array}$ \\
\hline$<1$ & 2 & 5,7 \\
$1-3$ & 12 & 34,3 \\
$4-6$ & 14 & 40 \\
$>6$ & 7 & 20 \\
\hline Total & 35 & 100,0 \\
\hline
\end{tabular}

\section{Jumlah laptop berdasarkan tingkat radiasi elektromagnetik}

Tabel 4 menunjukkan bahwa dari 35 jenis laptop, sebagian besar memiliki tingkat radiasi rata-rata 0,01-0,10 dengan jumlah 27 jenis laptop dan persentase sebesar 77,14\%.

Tabel 4. Jumlah laptop berdasarkan tingkat radiasi elektromagnetik.

\begin{tabular}{lcc}
$\begin{array}{l}\text { Tingkat } \\
\text { Radiasi }\end{array}$ & $\begin{array}{c}\text { Jumlah } \\
\text { Laptop (n) }\end{array}$ & Persentase(\%) \\
\hline $0,01-0,10$ & 27 & 77,14 \\
\hline
\end{tabular}


Jumlah responden berdasarkan keluhan kesehatan

Tabel 5 menunjukkan sebagian besar responden mengalami keluhan mata lelah sebanyak 29 orang (83\%). Responden dengan keluhan nyeri otot berjumlah 12 orang (34,3\%), sedangkan responden dengan keluhan sakit kepala berjumlah 7 orang (20\%) dan keluhan yang insomnia berjumlah 4 orang $(11,4 \%)$.

Tabel 5. Jumlah responden berdasarkan keluhan kesehatan.

\begin{tabular}{ccc}
\hline Keluhan & $\begin{array}{c}\text { Jumlah } \\
\text { Responden } \\
(\mathbf{N})\end{array}$ & $\begin{array}{c}\text { Persentase } \\
(\mathbf{\%})\end{array}$ \\
\hline Sakit kepala & 7 & 20 \\
Nyeri otot & 12 & 34,3 \\
Mata lelah & 29 & 83 \\
Insomnia & 4 & 11,4 \\
\hline
\end{tabular}

Korelasi Spearman antara radiasi beberapa laptop dan keluhan kesehatan

Penelitian ini menggunakan uji spearman yang mana pada hasil uji ini di peroleh nilai koefisien korelasi $\mathbf{r}_{\mathbf{s}}$ masingmasing $=0,435,0,129,0,340$, dan 0,259. Hasil ini menunjukkan bahwa secara statistik, tidak terdapat hubungan bermakna antara tingkat radiasi dan keluhan neurologis responden pengguna laptop.

\section{BAHASAN}

Penelitian ini dilaksanakan selama 2 bulan yaitu bulan November - Desember 2012 di gedung Pertamina dan Rusunawa Kampus Universitas Sam Ratulangi dengan mengambil subjek penelitian yaitu mahasiswa yang mnggunakan laptop dengan beberapa merek dan tipe yang berbeda. Pengukuran kuat medan magnet gelombang elektromagnetik dilakukan dengan menggunakan alat pengukur panjang gelombang elektromagnetik yaitu Electromagnetic Field Tester, dimana pada pengukuran ini semua sampel diukur pada keadaan yang sama yaitu laptop yang menyala.
Tabel 6. Korelasi radiasi laptop dengan keluhan kesehatan.

\begin{tabular}{|c|c|c|c|c|}
\hline \multirow{2}{*}{$\begin{array}{c}\text { Tingkat } \\
\text { radiasi } \\
(\mu \mathrm{T})\end{array}$} & \multicolumn{4}{|c|}{ Keluhan (N) } \\
\hline & $\begin{array}{c}\text { Sakit } \\
\text { kepala }\end{array}$ & $\begin{array}{c}\text { Nyeri } \\
\text { otot }\end{array}$ & $\begin{array}{l}\text { Mata } \\
\text { lelah }\end{array}$ & Insomnia \\
\hline $\begin{array}{c}0,01- \\
0,10\end{array}$ & 6 & 8 & 23 & 4 \\
\hline $\begin{array}{c}0,11- \\
0,20\end{array}$ & 1 & 3 & 2 & 0 \\
\hline $\begin{array}{c}0,21- \\
0,30\end{array}$ & 0 & 1 & 2 & 0 \\
\hline $\begin{array}{c}0,31- \\
0,40\end{array}$ & 0 & 0 & 0 & 0 \\
\hline $\begin{array}{c}0,41- \\
0,50\end{array}$ & 0 & 0 & 1 & 0 \\
\hline $\begin{array}{c}0,51- \\
0,60\end{array}$ & 0 & 0 & 0 & 0 \\
\hline $\begin{array}{c}0,61- \\
0,70\end{array}$ & 0 & 0 & 0 & 0 \\
\hline $\begin{array}{c}0,71- \\
0,80\end{array}$ & 0 & 0 & 0 & 0 \\
\hline $\begin{array}{c}0,81- \\
0,90\end{array}$ & 0 & 0 & 0 & 0 \\
\hline $\begin{array}{c}0,91- \\
1,00\end{array}$ & 0 & 0 & 0 & 0 \\
\hline $\begin{array}{c}1,01- \\
1,10\end{array}$ & 0 & 0 & 0 & 0 \\
\hline $\begin{array}{l}1,11- \\
1,20\end{array}$ & 0 & 0 & 0 & 0 \\
\hline $\begin{array}{c}1,21- \\
1,30\end{array}$ & 0 & 0 & 0 & 0 \\
\hline $\begin{array}{c}1,31- \\
1,40\end{array}$ & 0 & 0 & 1 & 0 \\
\hline Total & 7 & 12 & 29 & 4 \\
\hline
\end{tabular}

Selain itu untuk menghindari adanya faktor predisposisi yang mempengaruhi bila terdapat tegangan listrik dan alat-alat elektronik lainnya yang dapat menimbulkan gelombang magnet, maka penelitian ini ketika dilakukan pengukuran sekring listrik ataupun barang-barang elektronik yang dapat menganggu sinyal elektromagnetik dihindari. Selain itu jarak pengukuran yang dilakukan berkisar antara $30 \mathrm{~cm}$ dari laptop sehingga alat pengukur panjang gelombang electromagnetic fieid tester benar-benar dalam keadaan stabil $(0,00 \mu \mathrm{T})$. Pada penelitian ini masing-masing sampel diukur 3 kali, untuk menghindari kesalahan perhitungan peneliti, sehingga nilai yang didapatkan dari hasil pengukuran merupakan nilai yang dapat dipertanggungjawabkan. 
Berdasarkan hasil penelitian ini ditemukan bahwa tingkat radiasi pada 35 laptop yang menjadi subjek penelitian didapatkan yang tertinggi adalah $0,01-0,10$ $\mu \mathrm{T}$ sebanyak 27 laptop (77\%), 1,31-1,40 $\mu \mathrm{T}$ sebanyak 1 laptop dan yang terendah adalah 0,41-0,50 $\mu \mathrm{T}$ sedangkan untuk hasil penelitian berdasarkan keluhan, didapatkan bahwa keluhan yang banyak muncul adalah mata lelah dengan jumlah responden sebanyak 29 orang (83\%). Terdapat beberapa keluhan mata yang dapat ditimbulkan akibat penggunaan laptop. Sebuah survey nasional yang dilakukan oleh Optometry didapatkan lebih dari $14 \%$ pasiennya menunjukkan gejala mata sebagai hasil dari penggunaan laptop atau komputer. Gejala yang biasanya muncul yaitu mata lelah, sakit kepala, penglihatan kabur, sakit leher ataupun punggung. Grandjean dan Oborne membedakan keluhan dari pengguna visual display unit termasuk laptop menjadi 2 jenis, yaitu: visual discomfort (gejala mata terasa sakit, panas, lelah, sakit yang menusuk, dan pusing dan visual impairent (gejala penglihatan kabur, berkedip dan ganda). Seperti halnya alat elektronik lainnya laptop atau komputer mengemisi radiasi ion dan non-ion. Termasuk didalamnya emisi radiasi ultraviolet, infrared, X-ray dan frekuensi dari radio. Namun emisi radiasi dari laptop atau komputer seringkali sangat rendah sampai tidak terukur bahkan ada yang ditemukan berada dibawah level aman yang direkomendasikan. Tapi kenyataannya akibat durasi penggunaan laptop yang dilakukan oleh kebanyakan orang berlebihan dan tanpa istirahat maka gejala-gejala diatas lebih mudah timbul dan dapat berujung pada keluhan mata dan keluhan neurologis yang lebih lanjut. Selain itu menurut Grandjean penerangan yang tidak didesain dengan baik akan menimbulkan gangguan atau kelelahan penglihatan selama bekerja. Pengaruh dari penerangan yang kurang memenuhi syarat akan mengakibatkan kelelahan mata, kelelahan mental, keluhan pegal didaerah mata dan sakit kepala disekitar mata, kerusakan organ mata, dan gangguan mata lainnya. Sebuah penelitian yang dilakukan oleh Margaret E. Sears mendapatkan bahwa sekitar 3\% dari penduduk Kanada telah didiagnosa dengan sensitifitas lingkungan. Mereka biasa mengalami gangguan neurologis dan keluhan lainnya seperti mata berair, sakit kepala, kelelahan, nyeri, serta masalah pencernaan dan pernapasan. Sensitifitas terhadap lingkungan dapat berkembang secara bertahap setelah paparan kronis terhadap benda-benda atau bahanbahan kimia seperti pestisida, bahan kimia pelarut bahan kimia gas yang biasanya ditemukan dari karpet atau perabotan serta fenomena elektromagnetik. ${ }^{1,8 .}$

\section{SIMPULAN}

Tingkat radiasi terbanyak yang didapatkan pada 35 jenis laptop pada penelitian ini adalah 0,01-0,10 $\mu$ T.Keluhan kesehatan terbanyak yang di dapatkan pada penelitian ini adalah mata lelah dengan total responden 29 orang (83\%).Pada penelitian ini secara statistik tidak terdapat hubungan yang bermakna antara tingkat radiasi dan keluhankesehatan pada responden yang menggunakan laptop.

\section{UCAPAN TERIMA KASIH}

Penulis mengucapkan terima kasih kepada dr. Fransiska Lintong, M.Kes dan dr.Wenny Supit, Mrepro, Sp.And atas segala saran dan perbaikan yang telah diberikan. Terima kasih juga disampaikan kepada semua pihak yang baik secara langsung maupun tidak langsung telah menumbuhkan ide atau gagasan dalam pemikiran penulis serta membantu penulis menyelesaikan penelitian dan artikel ini.

\section{DAFTAR PUSTAKA}

1. Hendra. Octaviani DF. Keluhan Kesehatan Akibat Penggunaan Laptop Pada Mahasiswa FKM UI [homepage on the Internet]. Nodate [cited 2012 Des 01]. Available from: http://staff.ui.ac.id/system/files/users/dahen /publication/keluhankesehatanakibatpengg unaanlaptoppadamahasiswafkm.pdf 
2. Amanda. Zulkarnain. Peranan Laptop Support dalam mengurangi Kelelahan pada Pengguna Laptop. INSAN. 2012;14:98.

3. Rugratzz. Sejarah dan Penemu Laptop [homepage on the Internet]. 2011 [cited 2012 Des 01]. Available from:URL: http://forum.kompas.com/sains/50225sejarah-dan-penemu-laptop.html.

4. Anies. Electrical sensitivity. Jakarta: PT Elex Media Komputindo; 2005.

5. Grant L. Electrical sensitivity as an emergening illnss [homepage on the Internet]. 1997 [cited 2012 Des 01]. Available from: http://www.tldp.com/ info@townsendletter.com
6. Grant L. The electrical sensitivty handbook: How electromagnetic fields are making people sick. Prescott, Arizona: Weldon Publishing; 1995.

7. Rubin GJ, Das Munshi J, Wessely S. Electromagnetic hypersensitivity: a systematic review of provocationtudies. Psychosom Med. 2005;67(2):224-32.

8. Sears ME. The Medical Perpective on Enviromental Sensitive [homepage on the Internet]. 2007 [cited 2012 Des 01]. Available from: http: http://www.chrcccdp.gc.ca/sites/default/files/envsensitivity _en.pdf 